\title{
Biografia: do estado da arte à prática da escrita da vida em Jornalismo
}

Monica Martinez ${ }^{1}$

Resumo: $\mathrm{O}$ artigo discute, a partir da etimologia, os conceitos de biografia em áreas distintas do conhecimento, como Ciências Sociais e Literatura, enfocando as narrativas biográficas na perspectiva do Jornalismo. Neste âmbito, descreve as concepçōes jornalísticas atuais de perfil, memória, biografia, ensaio pessoal e narrativa de viagem, exemplificando-as. Em seguida, aborda a necessidade de aprofundamento da compreensão humana na construção biográfica, resgatando a noção de missão da cultura antiga grega e sua contraparte atual por meio da teoria do fruto do carvalho. Delineia também as visões psiquiátricas freudiana e junguiana, complementando-as com a questão da memória do ponto de vista da Mitologia, Neurologia e da Psicologia Social. As discussões são propostas no âmbito do tempo escalonado da Nova História. Para finalizar, dada a complexidade da reconstrução das narrativas biográficas, propõe-se o conhecimento de novas metodologias, como Jornada Humana, Biografia Humana e Teoria do Caos e dos Fractais.

Palavras-chaves: Comunicação; Jornalismo Literário; Biografia; Biografia Humana; Jornada do Herói.

\begin{abstract}
From an etymological starting point, the article aims to discuss the biographical concept in different areas of knowledge, such as Social Sciences and Literature, emphasizing the Journalistic approach, defining as well as giving examples of the present concepts of profile, memory, biography, personal essay, and travel writing. It suggests the need of a deeper understanding of the human being to the construction of biographical narratives, retracing the notion of mission from the antique Greek culture and its present version, Hillman's acorn theory. The paper briefly considers Freud's and Jung's Psychiatric perspective, complementing them with Mythology, Neurology, and Social Psychology studies about the memory. The time issue in the field of the biographical narratives is pointed out in the French New History context. Due to the complexity of the biographical narratives construction, the paper recommends the use of advanced methodolo 7 gical proposals, such as the Hero Journey, Human Biography, and the Chaos and Fractal Theory applied to the writing of life stories.
\end{abstract}

Keywords: Communication; Literary Journalism; Biography; Human Biography; Hero Journey.

1 Monica Martinez é pos-doutoranda do Poscom da Umesp. Doutora em Cièncias da Comunicação pela ECA-USP, é autora de Jornada do Henoi: estrutura narrativa mitica na construção de histórias de vida $\mathrm{cm}$ jornalismo (Fapesp/Annablume, 2008). É titular de Jornalismo Literário (UnjFIAMFAAM) e responsável pelo curso de Memória, Perfile Biografia (SJSP). E-mail martinez.monica@uol.com.br 
A palavra biografia contém um vasto aporte de reflexões sobre a arte de registrar, por meio da escrita, histórias humanas. Para começar, ela principia com bio, do grego bios, que significa vida. Tal anteposto, ou seja, partícula que inicia uma palavra, é ricamente representado nas línguas ocidentais - são 400 deles em português, de bioaeração a bioturbar. Sem contar os interpositivos - como abiogênese - e os pospositivos - caso de micróbio.

Há, portanto, uma explosão de vitalidade em torno do conceito bio, vida, que a rigor é o período compreendido entre o nascimento e a morte de um ser. Mas a palavra, claro, não se resume a este breve ciclo biológico. Tanto que meia coluna é a ela dedicada no Dicionário Houaiss de Lingua Portuguesa. De acordo com a obra, vida também se refere ao modo de viver, a hábitos.

Além do fator sociobiológico, a palavra vida também está relacionada ao aspecto psicofísico, portanto ao entusiasmo e ao prazer. Dizemos que uma pessoa cheia de vida é automotivada. Alguém ou algo vivaz é aquele ou aquilo que nos toca, que tem alma, entusiasmo, algo a mais.

O que vem antes e depois da vida tem sido alvo de especulações há pelo menos 80 mil anos, época a que remontam as primeiras tumbas surgidas na Galiléia, Oriente Médio (De Masi, 2005). Como espécie, somos histórica e profundamente apaixonados em tentar provar ou refutar a hipótese de que já fomos, somos e/ou continuaremos sendo um ser, numa multiplicidade criativa de configurações que remonta aos povos africanos e indo-europeus e atinge sua plenitude na contemporaneidade, com a habilidade do bomos consumidor de misturar tradições e montar a própria, de forma customizada.

Essa busca por um sentido surge há milênios. Contudo, seu boom começa há cerca de $1000 \mathrm{a}$. C., quando os povos gregos gradualmente passam a enfatizar menos o pensamento mítico, que brota da mentalidade coletiva (Eliade, 1989, 1992), em detrimento do histórico. Começa naquele momento um longo caminho em direção ao racionalismo e ao individualismo humano, que atinge o ápice em nossos dias. Não por acaso, esse processo de transição ocorre concomitantemente ao surgimento da escrita, ou graphia, pospositivo que completa a palavra biografia.

\section{Breve estado da arte}

Da mesma forma que as reflexões sobre a vida não são novas, o termo biografia também não o é. Ainda de acordo com o Dicionário Houaiss de Lingua Portuguesa, a palavra em grego, Biograpbia, 'relato de vidas', já é empregada pelo neoplatônico Damáscio (462 - 538 d. C.). O filósofo e historiador francês Charles du Fresne, também conhecido como Du Cange (1610-1688), cita o grego tardio 
biográphos, 'escritos de vidas'. De 1721 datam os primeiros registros da palavra em francês, biographie, e, sessenta anos mais tarde, 1781, em inglês, biograpby ${ }^{2}$.

O termo aparece, com mais semelhanças do que diferenças, em vários ramos do conhecimento científico. Em Ciências Sociais, que congrega áreas do saber como sociologia e antropologia, há grande preocupação metodológica. Neste contexto, o método biográfico recebe uma denominação mais ampla: histórias de vida.

A antropóloga brasileira Mirian Goldenberg explica que a expressão da história pessoal sintetiza de forma individual e ativa uma sociedade, reapropriando o universo social e histórico no qual a pessoa vive. De acordo com a pesquisadora, "é possível ler uma sociedade através de uma biografia", conhecer o social partindo-se da especificidade irredutível de uma vida individual (Goldenberg, 1999: 36-37). Essa dimensão social também é encontrada em outras áreas, como a Psicologia Social.

Na literatura, a "narração oral, escrita ou visual dos fatos particulares das várias

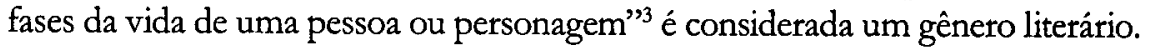

Em Comunicação Social, as reflexões acadêmicas sobre o tema são emergentes, sobretudo em Jornalismo. O motivo é que a prática de biografias por jornalistas é recente. Autor de Biografismo: reflexões sobre a escrita da vida, o pesquisador brasileiro Sérgio Vilas Boas (2008) ressalta que a chegada dos jornalistas ao campo data de 1982, quando Alberto Dines lança Morte no paraiso: a tragédia de Stefan Zweig pela Nova Fronteira.

A biografia sobre o escritor austríaco de ascendência judaica, que deixou a pátria sob ocupação alemã e auto-exilou-se no Brasil, onde se suicidou em 1942, abriu um campo promissor. Tanto que a década de 1990 é cenário de um boom biográfico, com o surgimento de grandes jornalistas-biógrafos, como Ruy Castro e Fernando Morais, para citar apenas dois exemplos.

Dada a importância do tema, sobretudo em Jornalismo Literário, o pesquisador brasileiro Edvaldo Pereira Lima propõe o gênero narrativas biográficas que, segundo o autor, consiste em seis subgêneros. Destacamos cinco ${ }^{4}$ : perfil, memória, biografia, ensaio pessoal e narrativas de viagem, que Lima chama de jornalismo literário de viagem (LIMA, 2008).

\subsection{Perfil: narrativa biográfica curta presentificada.}

Dentre estes cinco formatos biográficos, o mais empregado no jornalismo brasileiro é o perfil: "tipo de entrevista que utiliza aspectos biográficos e pessoais

2 Disponível em: < http://houaiss.uol.com.br/busca.jhtm?verbete=biografia\&stype $=\mathrm{k}>$. Acesso em: 5 nov. 2008.

3 Idem.

4 Na visão de Iima, o sexto subgênero das narrativas biográficas é a reportagem temática (Lima, 2008: 424). 
para mostrar ao público características, idéias, opiniões, projetos, comportamento, gostos e traços do entrevistado" (Barbosa; Rabaça, 2001: 560).

$\mathrm{Na}$ prática jornalística, o termo tem origem na revista estadunidense The New Yorker, que se não o inventa, ao menos o introduz na linguagem jornalística e eleva essa forma de narrativa biográfica curta à condição de arte:

It used to be said around the New Yorker offices that our founding editor, Harold Ross, invented the Profile. But if a Profile is a biographical piece - a concise rendering of a life through anecdote, incident, interview, and description (or some ineffable combination thereof) -, well, then, it's a little presumptuous to stick Ross at the front of the queue, ahead of Plutarch, Defoe, Aubrey, Strachey, or even The Saturday Evening Post. And yet in 1925, when Ross launched the magazine he liked to call his "comic weekly", he wanted something different - something sidelong and ironical, a form that prized intimacy and wit over biographical completeness or, God forbid, unabashed hero worships. Ross told his writers and editors that, above all, he wanted to get away from what he was reading in other magazines - all the "Horatio Alger" stuff.

James Kevin McGuiness, a staffer in the earliest days of the magazine, suggested the rubric "Profiles" to Ross. By the time the magazine got around to copyrighting the term, it had entered the language of American journalism (Remnick, 2000: ix) .

Convém ressaltar que o perfil aprofundado, uma tradição de longa data nos Estados Unidos, ressurge na atualidade brasileira. Depois da experiência do Jornal da Tarde e da revista Realidade, (Faro, 1999), volta a ser encontrado em publicações como as revistas Piaui, Brasileiro e Bravo!.

Mais comum no restante da mídia é uma forma mais superficial de perfil, que Muniz Sodré e Maria Helena Ferrari chamam de miniperfil. "Nesse caso, como o destaque é dado aos fatos, à ação ou ao levantamento de dados, os personagens são secundários: o relato é interrompido para dar lugar a um enfoque rápido sobre eles, sob forma de narrativa ou entrevista curta (Sodré; Ferrari, 1986: 139).

5

Costuma-se dizer nas redaçōes da New Yorker que nosso fundador, Harold Ross, inventou o Perfil. Mas se o Perfil é uma peça biográfica - uma versão concisa de uma vida por meio de relatos particulares, incidentes, entrevistas e descriçōes (ou alguma combinação inefável disso) - bem, entào, é um pouco presunçoso colocar Ross no início da fila, à frente de Plutarco, Defoc, Aubrey, Strachey ou mesmo do The Satırday Evening Post. Ainda assim, em 1925, quando Ross lançou a revista que elc gostava de chamar de "semanário cômico", ele queria algo diferente - algo à margem e irónico, uma forma que premiasse a intimidade e inteligéncia espirituosa mais do que a completude ou, Deus me livre, a adoração descarada de heróis. Ross falou a seus escritores e editores que, acima de tudo, ele queria fugir do que lia nas outras revistas - todas as coisas (excmplares) de "Horatin Alger".

James Kevin McGuiness, funcionário nos primeiros dias da revista, sugeriu a rúbrica "Perfis"a Ross. $\mathrm{Na}$ época em que a revista pediu os direitos autorais do termo, ele já havia entrado na linguagem do jornalismo americano. (Tradução livre da autora). 
Como narrativa biográfica curta, o perfil tende a ser presentificado e costuma surgir na mídia em função da evidência do indivíduo por algum motivo, como quando um ator ou diretor lança um filme ou um executivo empreende um negócio diferenciado.

Por isso, o perfil sempre está alinhado com o conteúdo ou linha editorial do veículo. É o caso do perfil escrito por Ricardo Kotscho (2008) sobre o historiador e jornalista Heródoto Barbeiro. OMonge da Notícia, publicado na revista Brasileiros, acompanha um dia de trabalho do profissional para relatar seu cotidiano cheio de atividades:

Falar com ele para combinar a matéria até que foi fácil. Em seu estilo objetivo e direto, deu o endereço de onde mora e avisou:

- Então, na quarta-feira, espero vocês lá em casa. Às 5 da matina.

Tão cedo não havia nem porteiro na área social. Para subir ao apartamento do nosso personagem, foi preciso descer até a garagem do velho prédio da Avenida Higienópolis, encostado no Pacaembu, um clássico dos anos 1950 com pastilhas na fachada, que já abrigou a aristocracia paulistana.

No horário combinado, ele apareceu todo lépido e sorridente, ainda ajeitando a gravata, na sala de visitas. Ao ver a nossa cara derrubada naquela hora precoce da manhã, os dois em pé admirando uma imagem de Buda que domina o ambiente, achou graça.

- Pensei que vocês tivessem desistido...

Ainda estava em tempo, até pensei nisso, mas valia a pena encarar o desafio de acompanhar um dia na vida dessa figura incomum no jornalismo brasileiro para tentar desvendar um mistério.

Como ele agüenta esta rotina, que começa no estúdio do Jornal da $C B N$, às 6 da manhã, e só vai terminar lá pelas 11 da noite, quando volta para casa depois de apresentar o Jornal da Cultura do outro lado da cidade? (Kotscho, 2008: 55-56).

Presente nos jornais, sobretudo nos encartes especiais e nas edições dominicais, o perfil ocorre com freqüência nas revistas de todos os tipos e, nas mídias eletrônicas, em magazines ou programas temáticos, caso do Globo Rural. Tem grande incidência na mídia digital: quase dois milhões de páginas resultam da busca com o termo perfil and jornalismo lançado no mecanismo de pesquisa Google.

\subsection{Memória: narrativa biográfica baseada em recordações.}

O formato memória ("exposição escrita ou oral de um acontecimento ou de uma série de acontecimentos mais ou menos seqüenciados; relato, narração")

6 Disponivel em: < http://houaiss.uol.com.br/busca.jhtm?verbete $=$ mem $\% F 3$ ria\&stype $=\mathrm{k}>$. Acesso
em: 5 nov 2008 . 
também conhecido como autobiografia ("narração sobre a vida de um indivíduo, escrita pelo próprio, sob forma documental ou ficcional") ', tem tido uso crescente.

Difere do perfil (mais voltado ao presente) e da biografia (preocupada em contar a trajetória de um individuo em sua totalidade) por ter a opção de se ater a parte da vida. Em geral é desenvolvida a partir de lembranças de uma época distante.

O enfoque principal da memória são as reminiscências, daí em geral serem escritas de forma intimista, em primeira pessoa. Esse formato pode levar o leitor a acreditar que se trata de trabalho escrito de próprio punho, quando muitas memórias são na verdade biografias, isto é, escritas por terceiros.

Seu suporte midiático por excelência é o livro, como os lançados por jornalistas que cobrem guerras, mas também podem aparecer em revistas. Um bom exemplo é a matéria Eu Estive na Guerra, onde o jornalista brasileiro José Hamilton Ribeiro faz um dramático relato da perda de parte da perna esquerda ao pisar numa mina terrestre na cobertura da Guerra do Vietnã (Ribeiro, 1968).

Para não cair, rodopiava sobre mim mesmo, em círculos e aos saltos. Instintivamente, levei as duas mãos para "acalmar" a minha perna esquerda, e foi então que a vi em pedaços. A calça no lado esquerdo tinha desaparecido. A visão foi terrível. O sangue brotava como de torneiras. Depois do joelho, a perna se abria em tiras, e um pedaço largo de pele retorcido estava no chão. Olhei em volta e não achei meu pé. Fiz um balanço rápido da situação. Senti a cabeça muito quente e um fio de sangue no rosto. A perna direita, empapada de sangue, parecia ferida, mas estava com a perna da calça e com a bota - senti certo alivio. A mão direita, muito queimada, minava sangue. Não senti absolutamente nenhuma dor. O que mais me incomodava era o incrível retesamento dos músculos da perna esquerda.

Shimamoto chegou-se a mim, puxou violentamente a minha cabeça para o seu peito - numa posição em que não mais podia ver a perna esquerda - e, chorando, beijava seguidamente os meus cabelos:

- José, oh José, oh José, como é que foi acontecer isso?

Uma idéia veio-me então bem nítida:

- Vou morrer!

Relembrei uma brincadeira de estudantes, quando combinamos que eu devia morrer com 32 anos.

- É, vou morrer.

De repente, ganhando espaço, devagar mais implacável, veio a dor. Uma dor aguda, sufocante, que me fazia suar aos borbotões. Gritei:

- Ajudem-me, ajudem-me. Preciso de morfina... (Ribeiro, 2008: 184-185). 
No ambiente digital, é presença cativa dos sites cooperativos, caso do São Paulo Minha Cidade, iniciativa da São Paulo Turismo, órgão municipal que convida cidadãos paulistanos a contar causos relacionados à capital do Estado (www.saopaulominbacidade.com.br).

\subsection{Biografia: narrativas integrais sobre vivos ou mortos.}

O formato biografia é um dos mais destacados no caso brasileiro. Sérgio Vilas Boas lembra que os jornalistas atuam há menos de 30 anos neste segmento (desde 1982), feito até então por historiadores e homens das letras.

A proposta do biógrafo é a de "contar toda a vida de uma pessoa, viva ou morta (Lima, 2008: 425). Há jornalistas consagrados na área, como Ruy Castro, defendem que a segunda categoria é a ideal:

Quanto à necessidade de o sujeito estar morto para ser biografável confiável, os motivos me pareceram óbvios. Com o biografado vivo, o autor tem a obrigação de ouvi-lo e de usá-lo como fonte. Supondo que o biografado tenha concordado com a biografia e se mostrado disposto a colaborar com o autor, "contando tudo", pode-se garantir que ele mentirá para o biógrafo. Talvez não o faça por mal, mas, como dizia Nelson Rodrigues, "todo mundo se olha no espelho e se enxerga num vitral” (Castro, 2007: 96).

A posição do biógrafo de Nelson Rodrigues (1992), Garrincha (1995) e Carmem Miranda (2005) deve-se ao fato de que ele e a editora Companhia das Letras foram processados pelos herdeiros do falecido jogador de futebol, Garrincha. $\mathrm{O}$ livro ficou 11 meses proibido de circular, sendo liberado somente em outubro de 1996. O processo, contudo, encerrou-se apenas em 2006, 11 anos depois do lançamento, mediante acordo entre as partes (Castro, 2007).

Caso semelhante, porém com desfecho diferente, ocorreu com a biografia do cantor brasileiro Roberto Carlos:

Paulo César de Araújo, seu biógrafo, escreveu um livro em que só faltou chamá-lo de santo, e teve o dissabor de ver seu livro proibido, destruído e enxovalhado - apenas porque Roberto Carlos não gosta que falem de sua vida, nem a favor. Imagine se Paulo César tivesse contado o que realmente sabia. (Castro, 2007: 96)

Apesar de a opinião do jornalista ser compreensível, no contexto do Jornalismo Literário entende-se que uma biografia desenvolvida a partir de um personagem vivo permite uma tiqueza de captação e narração ímpar.

Um dos diferenciais da produção biográfica sem dúvida é o estilo autoral, que imprime sabores únicos ao texto. Com estilo denso, construído a partir de 
intensa pesquisa, o jornalista Fernando Morais é biógrafo de Assis Chateaubriand (1994), de Olga (1995), dos fundadores da agência W/Brasil, Washington Oliveto, Llussá Ciuret e Gabriel Zellmeister (2005), do Marechal Montenegro (2006) e de Paulo Coelho (2008). Deste último livro, destaca-se a abertura, com reconstrução primorosa da chegada do escritor no aeroporto de Ferihegy, em Budapeste, para o lançamento de livro.

\subsection{Ensaio pessoal: tipo emergente de narrativa biográfica.}

Autobiografia reflexiva é uma definição para este formato derivado do ensaio tradicional, que discute um tema a partir de leituras e vivências do autor, em narrativa rica de ponderações e digressões.

A versão mais moderna desse gênero, no jornalismo literário atual, mescla narrativa e reflexão, sempre com forte conotação pessoal. Significa que o autor escreve sobre um tema por que há um motivo individual muito forte que o impele a fazer isso, de caráter emocional ou intelectual, ou ambos. Há uma necessidade premente de compreensão. (...)

O ensaio pessoal exige, portanto, muita coragem do autor. Disposição para despir-se por inteiro para o leitor. A humanização que se destaca nesse caso é a do próprio escritor, sua vulnerabilidade diante de acontecimentos sumamente tocantes. Revela-se frágil ou tomando consciência de seus limites, diante dos paradoxos da vida. Ele é o protagonista da sua própria história, mas não a conta, apenas. Filosofa. Mas faz isso de um patamar de necessidade orgânica profunda. O movimento para expor seu mundo interior procede das entranhas (Lima: 2008: 431-432).

O livro No Ar Rarefeito, do escritor e jornalista norte-americano Jon Krakauer, pode ser assim classificado. Em março de 1996, ele é enviado pela revista Outsider ao Nepal para participar de uma expedição ao monte Everest. Ao término da escalada, nove alpinistas, de quatro grupos diferentes (cinco dos quais companheiros da equipe de Krakauer), estavam mortos. A matéria de para a revista foi feita, mas ele explica na introdução da obra que:

Cumprida esta parte, tentei tirar o Everest de minha cabeça e da minha vida, mas foi impossível. Em meio a um nevoeiro de emoções confusas, continuei tentando dar um sentido ao que acontecera lá em cima e a martelar as circunstâncias em que meus companheiros morreram. (...) principalmente porque o que houve na montanha estava me roendo as entranhas. Pensei que, escrevendo o livro, poderia expurgar o Everest de minha vida. (Krakauer: 1997: 11-12).

Da mesma forma que o perfil, há ensaios pessoais menores em tamanho, que podem ser classificados como mini-ensaios pessoais. 


\title{
1.5. Narrativa de viagem: transformação por meio da interação.
}

A princípio, este item pode parecer deslocado nesta lista. Contudo, uma análise mais atenta revela que um número significativo de relatos de viagem tem natureza biográfica, pois:

Apresenta um grau de aproximação ao ensaio pessoal e aos textos de memórias porque é também, em essência, um texto biográfico. As viagens fazem parte de nossas vidas como um processo de descoberta do mundo e de nós mesmos. Quando vamos para lugares diferentes, especialmente àqueles onde encontramos pessoas de costumes muito distintos dos nossos, estamos também mergulhados num processo de definição de auto-identidade. Descobrir o outro é de certa forma descobrir facetas desconhecidas de nós próprios. Conhecer o outro, diferente de nós, é conhecer a todos nós, como membros da espécie humana. Por isso a viagem e sua expressão narrativa são processos de transformação (LIMA, 2008: 433).

O repórter Charles Martin Kearney, do The Missouri Review, narra este processo de autoconhecimento em Maps and Dreams (Mapas e Sonhos):

\begin{abstract}
Night in New Delhi
Suzanne and I were nearing the end of a journey together that had taken us overland through Turkey, Iran, Afghanistan, Pakistan, and India. On the front steps of a hotel in New Delhi, I waited for a taxi among shirtless, mostly sleeping baggage men. My documents and belongings were packed. The hotel restaurant had air conditioning, and moneychangers - the grafters and hawkers who made Asia possible and impossible - had already grouped together close to its locked entrance, smoking cheroots, aloof, edgy, and as watchful and nervous as birds. An oxcart stacked with bundles of cotton scraps passed us in the street. Early morning cooking fires, tended by squatters, tribes of sick and poor, provided checkpoints of light close to ground. Overhead, slow blue clouds hid the moon. (Kearney In: Kincaid, 2005: 201 ${ }^{8}$.
\end{abstract}

\footnotetext{
8 Suzanne e eu estávamos quase ao fim da viagem que nos tinha levado através da Turquia, Irã, Afeganistão, Paquistão e Índia. Nos degraus da frente de um hotel em Nova Delhi, eu esperava por um táxi entre carregadores sonados e sem camisa. Meus documentos e pertences estavam guardados nas malas feitas. $O$ restaurante do hotel tinha ar condicionado e os cambistas - trapaceiros e mascates que tornam a Ásia possivel e impossivel - já tinham se agrupado próximos à entrada trancada, fumando charutos com duas pontas cortadas, distantes, irritados, tão alertas e ariscos quanto pássaros. Um carro de boi com sacos de algodão empilhados passou por nós na rua. Fogos, acesos bem cedo para cozinhar, lançavam sua fumaça em direção às pessoas agachadas, tribos de doentes e pobres, provendo pontos de luz próximos ao solo. Acima, nuvens azuis lentas encobriam a lua. (tradução livre da autora).
} 
A partir da descrição dessa noite em Delhi, o jornalista descreve não apenas sua experiência de viagem, mas também o desfecho de um relacionamento amoroso de férias.

\section{A matéria da memória: ser humano, espaço e tempo}

Mas qual é a base a partir da qual são criadas as narrativas biográficas? Segundo o historiador francês Jacques Le Goff, a matéria memorável está baseada no triplo problema do homem, do tempo e do espaço (Leroy-Gourhan apud Le Goff, 2003: 429).

Não por acaso, qualquer que seja a estrutura da narrativa biográfica, a compreensão do ser humano é vital para os interessados em se aventurar na arte da escrita da vida. Salutar, portanto, a visão transdisciplinar, que acolhe saberes de outras áreas do conhecimento.

Provém da mitologia grega, por exemplo, a noção de destino, imutável pois que gravado em ferro e bronze. Cabia às Moiras (depois Parcas para os romanos) - as circunspectas e implacáveis irmãs Cloto, Láquesis e Atropos - respectivamente fiar, tecer e cortar o fio da vida, dando forma e limite à existência dos humanos. (Commelin, s/d).

Conforme evolui, a cultura grega incorpora esta noção de missão, que permeia o imaginário humano até nossos dias. Quando a deusa Atena incita Telêmaco a buscar o pai, ela não está apenas dando ao jovem uma tarefa concreta, mas um compromisso psicológico: o de descobrir suas origens e assumir seu papel. Com a volta de Ulisses e o fim dado aos pretendentes da mãe, a paz volta à Ítaca (Homero, 2002).

Esse conceito de missão aflora em várias configurações e épocas, como nos cruzados na Idade Média, nos puritanos que emigraram para o Novo Mundo e nas levas imigratórias americanas que aportaram no Brasil no século 19 (Oliveira, 1995), entre outros.

O psicólogo junguiano James Hillman, idealizador da psicologia arquetípica, chama este conceito de teoria do fruto do carvalho:

\footnotetext{
"Mais cedo ou mais tarde, alguma coisa parece nos chamar para um caminho específico. Essa "coisa" pode ser lembrada como um momento marcante na infância, quando uma urgência inexplicável, um fascínio, uma estranha reviravolta dos acontecimentos teve a força de uma anunciação: isso é o que devo fazer, isso é o que preciso ter. Isso é o que sou (Hillman, 1997: 13).
}

A compreensão do ser humano é revolucionada por Sigmund Freud (18561939) e seu método da psicanálise (Pena, 2008). Em adição à noção de consciente, 
o neurologista judeu-tcheco propõe o conceito de inconsciente pessoal, depositário de recalques e repressões que o indivíduo, em estado de vigília, não tem acesso.

A ponte entre as memórias consciente e latente seria feita por meio dos sonhos, entre outros recursos. Freud atribui grande importância à infância, em particular aos traumas desta fase da vida, e à sexualidade na reconstituição desta memória suprimida.

Um de seus contemporâneos, o psiquiatra suíço Carl Gustav Jung (18751961), tem visão diferente, porém, no meu entender, complementar à de Freud. Jung acolhe a proposta freudiana do inconsciente pessoal, mas entende-a como a parte mais superficial do inconsciente coletivo:

O inconsciente coletivo é uma parte da psique que pode distinguir-se de um inconsciente pessoal pelo fato de que não deve sua existência à experiência pessoal, não sendo portanto uma aquisição pessoal. Enquanto o inconsciente pessoal é constituído essencialmente de conteúdos que já foram conscientes e no entanto desapareceram da consciência por terem sido esquecidos ou reprimidos, os conteúdos do inconsciente coletivo nunca estiveram na consciência e portanto não foram adquiridos individualmente, mas devem sua existência apenas à hereditariedade (Jung, 2000: 53).

Por paradoxal que seja, a emergência das mídias digitais permite, por analogia, compreender a proposta epistemológica de Jung. Hoje o internauta mantém em seu computador pessoal apenas uma fração do conteúdo compartilhado na rede. O conceito, que em biologia é compreendido como mente expandida, é defendido pelo inglês Rupert Sheldrake, atual diretor do The Perrott-Warrick Research Project, do Trinity College, em Cambridge, UK (Sheldrake, 1991).

Para Jung, o inconsciente coletivo é formado por arquétipos:

O conceito de arquétipo, que constitui um correlato indispensável na idéia do inconsciente coletivo, indica a existência de determinadas formas na psique, que estão presentes em todo o tempo e em todo o lugar. A pesquisa mitológica denomina-as "motivos" ou "temas"; na psicologia dos primitivos elas correspondem ao conceito de représentations collectives de Levy-Brühl e no campo das religiões comparadas foram definidas como "categorias de imaginação" por Hubert e Mauss. Adolf Bastian designou-as bem antes como "pensamentos elementares" ou "primordiais". A partir dessas referências torna-se claro a minha representação de arquétipo - literalmente uma forma preexistente - não é exclusivamente um conceito meu, mas também é reconhecido em outros campos da ciência (Jung, 2000: 53-54). 
Um exemplo é o arquétipo materno, que pode se configurar em inúmeras formas, da própria mãe e avó à madrasta e sogra, passando por babás ou transferências mais elevadas, como deusas e santas, como a Virgem Maria dos cristãos.

Embora Jung atribua importância à fase inicial da vida, a ênfase do psiquiatra suíço recai sobre a maturidade. Isso porque a psicologia analítica visa a compreensão do processo de individuação, entendido como a integração das várias instâncias psíquicas do ser humano. Aluna de Jung, a psiquiatra brasileira Nise da Silveira (1906-1999) explica o conceito:

Todo ser tende a realizar o que existe nele, em germe, a crescer, a completar-se. Assim é para a semente do vegetal e para o embrião do animal. Assim é para o homem, quanto ao corpo e quanto à psique. Mas no homem, embora o desenvolvimento de suas potencialidades seja impulsionado por forças instintivas inconscientes, isso adquire um caráter peculiar: o homem é capaz de tomar consciência desse desenvolvimento e de influenciá-lo. Precisamente no confronto do inconsciente com o consciente, no conflito como na colaboração entre ambos é que os diversos componentes da personalidade amadurecem e unem-se numa síntese, na realização de um indivíduo específico e inteiro. Essa confrontação "é o velho jogo do martelo e da bigorna: entre os dois, o homem, como o ferro, é forjado num todo indestrutivel, num individuo. Isso, em termos toscos, é o que eu entendo por processo de individuação (Jung). (Silveira, 2000: 77).

O processo de individuação permite a ativação plena do Self, o centro da personalidade. Para isso, devem ser integradas, por meio da conscientização, outras instâncias psíquicas, como a persona (máscara útil para o ser social, mas que pode predominar sobre as outras instâncias, se enfatizada) e a sombra (parte animalesca, primitiva e não aceita do ser, projetada no outro).

A biografia de Jung sintetiza a jornada pessoal do psiquiatra:

Não concordo quando dizem que sou um sábio ou um "iniciado". (..) A diferença entre a maioria dos homens e eu reside no fato de que em mim as "paredes divisórias" são transparentes. É uma particularidade minha. Nos outros, elas são muitas vezes tão espessas, que lhes impedem a visão; eles pensam, por isso, que não há nada do outro lado. Sou capaz de perceber, até certo ponto, os processos que se desenvolvem no segundo plano; isso me dá segurança interior. Quem nada vê não tem segurança, não pode tirar conclusão alguma, ou não confia em suas conclusões. Ignoro o que determinou minha faculdade de perceber o fluxo da vida. Talvez tenha sido o próprio inconsciente, talvez os meus sonhos precoces, que desde o início marcaram meu caminho (Jung, 1989: 307). 
Outra particularidade do psiquiatra suíço era sua notável memória: suas primeiras lembranças remontam aos dois ou três anos de idade (Jung, 1989: 21).

\subsection{O espaço da memória}

Os estudos das narrativas biográficas perpassam pela questão da memória coletiva e individual, como sugere Le Goff:

Em todas sociedades, os indivíduos detêm uma grande quantidade de informações no seu patrimônio genético, na sua memória de longo prazo e temporariamente, na memória ativa (Le Goff, 2003: 421).

Nas sociedades primevas, mergulhadas no pensamento mítico, predomina a memória coletiva. Esta se ordena por três grupos de interesses principais: mitos de origem (que lidam com a idade coletiva do grupo); prestígio das famílias dominantes (com a ênfase nas genealogias) e transmissão do saber técnico (em geral por meio de fórmulas ligadas à magia religiosa (Le Goff, 2003: 427).

$\mathrm{Na}$ mitologia, o estadunidense Joseph Campbell identifica quatro funções dos mitos: pedagógica, ensinando o ser a vivenciar a vida humana sob qualquer circunstância; sociológica, dando suporte e validando a determinada ordem social; cosmológica, mostrando os mecanismos e a forma de funcionamento do universo; e mística, funcionando como um portal para a transcendência, a dimensão do mistério (Campbell,1990:32).

Com a transição do pensamento mítico para o histórico, o conteúdo das memórias deixa de ser coletivo, migrando gradualmente para o individual. O registro das visões das elites continua preponderante, porém, dando surgimento aos registros reais e urbanos (Le Goff, 2003), depois ao das elites burguesas, muitos destes apoiados pela nascente mídia.

Do ponto de vista cerebral, o neurologista argentino Ivan Izquierdo, do Centro de Memória do Instituto de Pesquisas Biomédicas da PUC-RS, explica que há basicamente dois tipos de memória. A memória de curto prazo ou de trabalho permite informação instantânea, que sobrevive o tempo necessário para ser utilizada. Mais importante para os estudos das narrativas biográficas, a memória de longo prazo armazena informações de forma mais durável (Izquierdo, 2002).

Ámbos sistemas são ligados, transferindo dados um para o outro, e o caminho para a memória de trabalho se tornar uma memória de longo prazo é seu valor. Sem ele, a informação é descartada. Trata-se de sistema digital-analógico: a memória como um todo é digital, porém sua fixação é analógica. O processamento fisioquímico abre ou reforça caminhos abertos por meio das sinapses neuronais. $E$ o uso que fixa e renova o sistema.

É importante ressaltar que em narrativas biográficas não estamos trabalhando na esfera da primeira realidade, biofisioquímica, mas no da segunda re- 
alidade, portanto o biógrafo atua na reconstruçào de uma realidade simbólica, cultural, nascida da relação entre a objetividade e a subjetividade, a imaginação e a razão, como propõe o comunicólogo brasileiro José Eugenio de Oliveira Menezes, do programa de Mestrado da Faculdade Cásper L_íbero, a partir da visão do semioticista tcheco Ivan Bystrina:

Ivan Bystrina, a partir da antropologia, está preocupado em descrever raizes, em localizar fatores "fundadores" da Segunda Realidade. Assim, descreve a cultura como "conjunto de atividades que ultrapassam a mera finalidade de preservar a sobrevivencia material" e garantem a "superação do medo existencial". No universo dos "textos imaginativos e criativos", conseguimos cuidar de nossa sobrevivéncia psíquica ou, em outras palavras, superar o constante desafio da morte (Menezes, 2007: 32).

Talvez a questão mais instigante sobre memória seja nào o conteúdo que lembramos, mas o que não lembramos. "O pensador italiano Norberto Bobbio dizia que 'somos aquilo que lembramos'. Eu costumo acrescentar 'e também somos o que decidimos esquecer'." (Izquierdo, 2004: 3).

Ou optamos por omitir. Ao pesquisar as memórias de Carl Jung, o pesquisador inglês Sonu Shamdasani ressalta que a obra, comercializada desde seu lançamento em 1961como uma autobiografia, é na verdade uma biografia realizada por Aniela Jaffé, ex-paciente e secretaria de Jung na fase final de sua vida. Ela teria tido uma participação muito maior do que apenas a de compilar os dados e prefaciálos, como aparece na capa do livro (Shamdasani, 2008). Jaffé teria suprimido fatos comprometedores à imagem pública de Jung, já octagenário na época.

Quanto ao acervo da memória, é importante lembrar a existência de patologias que alteram não apenas o acervo, mas também a percepção de realidade, como explica o neurologista estadunidense Oliver Sacks:

Cada um de nós é uma biografia, uma história. Cada um de nós é uma narrativa singular que, de um modo contínuo, inconsciente, é construída por nós, por mejo de nós e em nós - por meio de nossas percepçōes, sentimentos, pensamentos, ações e, nào menos importante, por nosso discurso, nossas narrativas faladas. Biologicamente, fisiologicamente, não somos muito diferentes uns dos outros; historicamente, como narrativas, cada um de nós é único (Sacks, 1997: 129).

A questão da identidade, a consciência de si mesmo, é vital na contemporaneidade. E essa noção emerge no processo de vinculação, ou seja, na relação com o outro. A filósofa brasileira Marilena Chauí lembra que o tempo da memória é o social, "não só porque é o calendário do trabalho e da festa, do cvento político e do fato insólito, mas também porque repercute no modo de lembrar: 
Descrevendo a substância social da memória - a matéria lembrada - você nos mostra que o modo de lembrar é individual tanto quanto social: o grupo transmite, retém e reforça as lembranças, mas o recordador, ao trabalhá-las, vai paulatinamente individualizando a memória comunitária e, no que lembra e no como lembra, faz com que fique o que signifique (Chauí, 1999: 31).

Assim, individuais ou comunitárias, as lembranças estão inseridas no espaço social, mas também no temporal.

\subsection{O tempo da memória}

Desde o surgimento da História, há quase 2.500 anos, o tempo tem sido considerado linear, gradual e progressivo. Contudo, há outras formas mais adequadas à produção de narrativas biográficas de compreendê-lo.

Uma delas é a proposta da Nova História Francesa, surgida nos anos 1950, também conhecida como Escola dos Annales por estar ligada ao periódico académico Revue des Annales. O historiador francês Fernand Braudel (1902-1985), um dos expoentes do movimento, defende a idéia de que, como no mar, há três camadas históricas e não apenas uma. A superfície representaria os acontecimentos cotidianos, rápidos e buliçosos; o leito do mar as décadas, que mudam lentamente e, portanto, são mais fáceis de serem percebidas pelo sujeito histórico; já as abissais camadas marítimas as grandes transformações sociais, que levam séculos ou milênios para ocorrerem e serem notadas.

Assim, chegamos a uma decomposição da história em planos escalonados. Ou, se quisermos, à distinção, no tempo da história, de um tempo geográfico, de um tempo social, e de um tempo individual (Braudel, 1992: 15).

Convém lembrar que ainda são raras as narrativas biográficas que mergulham no profundo tempo geográfico, que permitiria ao leitor a compreensão do ser humano dentro da complexa aldeia cada vez mais global e cheia de teias relacionais. Dos autores contemporâneos, talvez o que mais se aproxime deste tempo seja o jornalista estadunidense John McPhee, uma referência em Jornalismo Literário (McPhee, 1996).

Afinal, por que a ênfase nas narrativas biográficas, numa sociedade midiatizada e digital em que impera o espaço do aqui e o tempo do agora? Uma possível resposta está no filme estadunidense Blade Runner, dirigido em 1992 por Ridley Scott e aqui traduzido por Caçadores de Andróides.

Passado num futuro sinistro, os humanos criam replicantes para as tarefas pesadas de colonização espacial. A instabilidade emocional e falta de empatia 
destes robôs sofisticados os deixa agressivos e a vida desses seres é limitada a quatro anos. Um motim contra esse curto prazo de validade leva os replicantes a invadirem uma zona proibida, a Terra, para negociar o aumento da vida com seu criador. A invasão leva à criação de uma força tarefa policial, os blade runner's do título, para exterminá-los.

Uma das cenas mais fortes do filme é a fala do replicante interpretado pelo ator Rutger Hauer, inconformado porque sua vida está acabando. Angustiado, ele lamenta que as maravilhas que havia visto nas galáxias mais distantes, que nem olhos humanos poderiam visualizar, não teriam duração no espaço e no tempo. Perder-se-iam. A dor do andróide se explica. Seja no campo das narrativas ficcionais ou nas não-ficcionais, esquecer é morrer. Se a morte ceifa a vida física, o esquecimento mata a simbólica. A necessidade de manter os registros da espécie humana, sobretudo os anônimos e cotidianos, talvez seja uma das razões da explosão de blogs e outras ferramentas midiáticas digitais.

Como fazer este resgate em tempos de tamanha complexidade? Seja de celebridades ou de heróis do cotidiano, o fato é que a reconstrução de vidas humanas contemporâneas, com a dignidade que merecem, pode se beneficiar com as metodologias compreensivas e aprofundadas que estão sendo pesquisadas e usadas na práxis jornalística. É o caso da Jornada do Herói, da Biografia Humana (Martinez, 2008) e da teoria do Caos e dos Fractais aplicadas à construção biográfica (Pena, 2003). 


\section{Referências}

O CAÇADOR DE ANDRÓIDES (BLADE RUNNER). Direção: Ridley Scott. Roteiro: Hampton Francher e David Webb Peoples, baseado em livro de Philip K. Dirk. Com Harrison Ford, Rutger Hauer, Sean Young, Edward James Olmos, M. Emmet Walsh e Daryl Hannah. Estados Unidos: 1982. Cor. (118 min.). Legendado. Port.

BARBOSA, Gustavo Guimarães; RABAÇA, Carlos Alberto. Dicionário de Comunicaşão. São Paulo: Campus, 2001.

BRAUDEL, Fernand. Escritos sobre a História. São Paulo: Perspectiva, 1978.

CAMPBELL, J. (com Bill Moyers) O Poder do Mito. São Paulo: Palas Atena, 1990.

CASTRO, Ruy. O Biografado dos Sonhos Precisa Ser... filho único, órfão, solteirão, estéril e brocha - única maneira de o biógrafo ficar a salvo de encrencas. Revista Brasileiros. São Paulo, n. 6, p. 95-98, dez 2007.

CHAUÍ, Marilena. Os trabalhos da memória. In: BOSI, Ecléa. Memória e Sociedade: lembraņa de velhos. São Paulo: Companhia das Letras, 3a. edição, 1999.

COMMELIN, P. Nova Mitologia Grega e Romana. Rio de Janeiro: Edições de Ouro, s/d.

DE MASI, Domenico. Criatividade e Grupos Criativos. Rio de Janeiro: Sextante, 2005.

ELIADE, Mircea. Aspectos do Mito. Lisboa: Edições 70, 1989. . Mito do Eterno Retorno: Cosmo e História. São Paulo: Mercuryo, 1992.

FARO, J.S. Revista Realidade 1966-1968: tempo da reportagem na imprensa brasileira. Porto Alegre: AGE, 1999.

GOLDENBERG, Mirian. A Arte de Pesquisar: como fazer pesquisa qualitativa em Ciências Sociais. Rio de Janeiro: Record, 1999.

HILMANN, James. O Código do Ser: uma busca do caráter e da vocação pessoal. Rio de Janeiro: Objetiva, 1997.

HOUAISS, Antonio; VILLAR, Mauro de Salles. Dicionário Houaiss de Lingua Portuguesa. Rio de Janeiro: Objetiva 2001.

HOMERO. Odisséia. São Paulo: Nova Cultural, 2002.

IZQUIERDO, Ivan. Memória. São Paulo: Artmed, 2002.

. A Mente Humana. Outubro de 2004. Disponível em <http://www. multiciencia.unicamp.br/artigos_03/a_01_.pdf>. Acesso em: 4 nov. 2008.

JUNG, C. G. Os Arquétipos e o Inconsciente Coletivo. Petrópolis: Vozes, 2000.

Memórias, Sonbos e Reflexões. Compilação e prefácio de Aniela Jaffé.

Rio de Janeiro: Nova Fronteira, 1989.

KINCAID, Jamaica (editor). The Best American Writing. New York: Houghton Mifflin Company, 2005.

KOTSCHO, Ricardo. O Monge da Notícia. Revista Brasileiros. São Paulo, n. 8, p. 55-63, mar 2008. 
KRAKAUER, Jon. No Ar Rarefeito: um relato da tragédia do Everest em 1996. São Paulo: Companhia das Letras, 1997.

LE GOFF, Jacques. História e Memória. Campinas/SP: Unicamp. 2003.

LIMA, Edvaldo Pereira. Páginas Ampliadas: O Livro-Reportagem como Extensào do Jornalismo e da Literatura/Jornalismo Literário. $4^{\text {a }}$. edição revista e ampliada. Barueri/SP: Manole, 2008.

MAILER, Norman; MAILER, John Buffalo. O Grande Važio. São Paulo: Companhia das L_etras, 2008.

MARTINEZ, Monica. Jornada do Heröi: Estrutura Narrativa Mitica na Construção de Histórias de Vida em Jornalismo. São Paulo: Annablume/Fapesp, 2008.

MCPHEE, John. The Second John MaPhee Reader: New York: The Noonday Press, 1996.

MENEZES, José Eugenio de O. Rádio e Cidade: L'inculos Sonoros. São Paulo: Annablume, 2007.

MORAIS, Fernando. O Mago. São Paulo: Planeta do Brasil, 2008.

MORIN, E. et al. A Inteligência da Complexidade. São Paulo: Peirópolis, 2000.

OLIVEIRA, Ana Maria Costa de. O Destino (näo) Manifesto: os imigrantes norteamericanos no Brasil. São Paulo: União Cultural Brasil-Estados Unidos, 1995.

PENA, F. "Biografias em Fractais": múltiplas identidades em redes flexiveis e inesgotáveis. Anais do Xll Encontro da Associação Nacional dos Programas de Pós-Graduação em Comunicação. Recife/PE, 2003.

. O Jornatismo Literário nas imagens de Freud e Lacan: por uma teoria psicanalítica do jornatismo. Anais do $31^{\circ}$. Congresso Brasileiro de Cièncias da Comunicaçào. Natal-RS, setembro de 2008. São Paulo: Intercom, 2008. [cd-rom].

REMNICK, David (edited by. Liffe Stories: profiles from The New Yorker: New York: Random House, 2000.

RIBEIRO, José Hamilton. Eu Estive na Guerra. Revista Realidade. São Paulo, maio de 1968.

. O Repórter do Século. São Paulo: Geração Editorial, 2006.

SACKS, Oliver. O bomem que confundin sua mulber com um cbapéu. São Paulo: Cia das Letras, 1997.

SHELDR AKE, Rupert. O Renascimento da Naturęa: O reforescimento da ciència $e$ de Ders. São Paulo: Cultrix, 1991.

SILVA, Diana Cristina Damasceno Lima. "Entre múltiplos eus: os espaços da complexidade". Tese de Doutorado. Rio de Janeiro: PUC, 1999.

SILVEIRA, Nise da. Jung: Lida e Obra. Rio de Janeiro: Paz e Terra, 1997.

SODRÉ, Muniz; FERRARI, Maria Helena. Técnica de Reportagem: notas sobre a narrativa jornalística. São Paulo: Summus, 1986.

SHAMDASANI, Sonu. Memórias, Sonhos e Omissòes. In: <http://www. rubedo.psc.br/Artigos/memorias.htm>. Acesso em: 4 nov. 2008. 
VILAS BOAS, Sergio. Biografias \& Biografos: jornalismo sobre personagens. São Paulo: Summus, 2002. . Biografismo: reflexões sobre a escrita da vida. São Paulo: Unesp, 2008. . Perfis: e como escrevê-los. São Paulo: Summus, 2003. 